\title{
Starting Insulin in Type 2 Diabetes: Real-World Outcomes After the First 12 Months of Insulin Therapy in a New Zealand Cohort
}

\author{
Shekhar Sehgal • Manish Khanolkar
}

To view enhanced content go to www.diabetestherapy-open.com Received: December 31, 2014 / Published online: February 14, 2015

(C) The Author(s) 2015. This article is published with open access at Springerlink.com

\section{ABSTRACT}

Aims: Currently, there is no consensus on which form of insulin to use when initiating insulin in type 2 diabetes (T2D). Our aim was to compare glycated hemoglobin (HbA1C) reduction, weight change and severe hypoglycemia rates during the first year after initiation of intermediate-acting insulin isophane, insulin glargine and pre-mixed insulin in patients with T2D.

Methods: Electronic clinical records of patients with T2D, starting insulin at a tertiary referral center in Auckland, New Zealand, from January 1 to December 31, 2012, were retrospectively evaluated. Primary outcomes were HbA1C

Electronic supplementary material The online version of this article (doi:10.1007/s13300-015-0100-8) contains supplementary material, which is available to authorized users.

S. Sehgal $(\square)$

Diabetes and Endocrinology registrar, Department of Endocrinology and Diabetes, Waikato Hospital, Hamilton, New Zealand

e-mail: shrike59@gmail.com

M. Khanolkar

Greenlane Clinical Centre, 1142 Auckland,

New Zealand

e-mail: ManishK@adhb.govt.nz reduction at 12 months and number of hospital admissions for hypoglycemia.

Results: Of 339 eligible patients, 273 (80.5\%) started on intermediate insulin, 24 started on insulin glargine and 42 started on pre-mixed insulin. The mean $\mathrm{HbA} 1 \mathrm{C}$ at insulin initiation was $89-95 \mathrm{mmol} / \mathrm{mol}$, but had decreased at 12 months by $26.6 \mathrm{mmol} / \mathrm{mol}$ with insulin glargine, $23.4 \mathrm{mmol} / \mathrm{mol}$ with pre-mixed insulin and $16.6 \mathrm{mmol} / \mathrm{mol}$ with insulin isophane ( $p<0.05$ vs. baseline for all groups). Patients on insulin glargine were more likely to achieve the HbA1C target of $<55 \mathrm{mmol} / \mathrm{mol}$ compared with patients on insulin isophane $(16.7 \%$ vs. $4.8 \%$; $p=0.04)$. Persistence rates were higher in patients initiated on pre-mixed insulin vs. insulin isophane (90.5\% vs. $69.6 \% ; p=0.01$ ). After controlling for confounding variables, glargine was more likely to achieve an HbA1C target of $<55(p=0.05)$.

Conclusions: All insulin types caused a significant reduction in $\mathrm{HbA1C}$, but very few met HbA1C targets. Insulin isophane was the most common type of insulin prescribed at initiation, with comparable outcomes to other types of insulin. More observational studies are needed to explore the possible impact of using other insulin types at initiation. 
Keywords: Glycated hemoglobin; Hypoglycemia; Insulin glargine; Insulin isophane; Pre-mixed insulin; Type 2 diabetes

\section{INTRODUCTION}

Type 2 diabetes (T2D) is a disease characterized by progressive beta cell decline [1]. Few oral antidiabetic drugs preserve beta cell function, therefore, $5-6 \%$ of all patients with T2D progress to requiring insulin injections every year worldwide [1]. Insulin therapy is associated with a significant and persistent reduction of glycated hemoglobin (HbA1C) across all groups. Starting insulin reduces microvascular and macrovascular complications in T2D [2]. Guidelines from the International Diabetes Federation (IDF) recommend that patients start on insulin when they have an HbA1C in excess of $65 \mathrm{mmol} / \mathrm{mol}$ on dose-optimized oral hypoglycemic therapy [3], but in reality many patients do not start insulin until their HbA1c level is far in excess of this threshold. In addition, there is a lack of consensus between guidelines on the optimal approach to initiating insulin. The IDF guidelines recommend starting with a long-acting basal insulin analog, with pre-mixed insulin for those with higher HbA1C. In contrast, the UK National Institutes of Clinical Excellence (NICE) guidelines recommend human insulin, based principally on cost considerations, rather than any apparent benefit seen in clinical trials [4].

Beginning with the addition of biphasic, prandial, or basal insulin to oral therapy in type 2 diabetes (4T) trial (trial number ISRCTN51125379) in 2007 [5], there have been several randomized control trials on insulin initiation in T2D for patients on dose-optimized oral hypoglycemic therapy [5-7]. These all trials share many similarities, including similar limitations. All are open-label trials, often comparing a basal analog/intermediate-acting insulin with prandial insulin and mixed insulin, many share the same endpoints, and a significant proportion are non-inferiority trials. Insulin is most often commenced for patients in primary care, where protocols on insulin initiation differ markedly to trial protocols. In clinical trials, insulin dose adjustment can be patient- or physician-controlled and based on a strict titration guideline in response to regular blood sugar testing. In contrast, in clinical practice, physicians are mostly responsible for dose titration. The frequency of follow-up and adherence to treatment and diabetes selfmanagement is much higher in clinical studies, and cannot be replicated in everyday practice. Therefore, in clinical trials, the outcomes of insulin initiation often differ markedly to those reported in large observational studies of clinical practice.

Large cohort and observational studies allow one to see the outcomes of insulin initiation in a real-world setting. Observational studies also have less stringent inclusion criteria and often include patients with end-organ dysfunction that trials would normally exclude. In the First Basal Insulin Evaluation (Fine ASIA) study, most patients initiating insulin therapy had had diabetes for 9 years [8]. Most of these patients had severe hyperglycemia and concomitant microvascular complications. The mean HbA1C reduction was around 1.5\% [8], similar to figures from other large cohort studies such as the $A_{1}$ chieve study [9]. This amount of HbA1C reduction was similar across all groups regardless of the type of insulin used. In observational studies, starting or switching to insulin analogs was associated with low rates of hypoglycemia and low weight gain $[8,9]$.

The aim of this study was to evaluate the process and clinical outcomes of insulin initiation in a real-world clinical scenario in 
New Zealand. HbA1C lowering efficacy and rates of meeting a predetermined HbA1C target, weight change and severe hypoglycemia rates requiring hospital admission at 1-year post-insulin initiation were evaluated. In addition, the influence of patient factors, such as HbA1C at initiation, duration of T2D, age and ethnicity on the physician's choice of insulin was evaluated.

\section{METHODS}

\section{Study Design}

A retrospective analysis of the electronic medical records from patients with T2D, attending the tertiary clinical center at the Auckland District Health Board between January 1, and December 31, 2012 was conducted. The following data were collected at the initiation of insulin therapy and 1 year later: patient demographics, anthropometric data, microvascular and macrovascular complications at the time insulin initiation, details of hospital admissions for hypoglycemia in the 12 months after insulin initiation, change in weight, persistence with prescribed insulin and whether patients achieved the predetermined HbA1C target of $<55 \mathrm{mmol} / \mathrm{mol}$.

This article does not contain any new studies with human or animal subjects performed by any of the authors.

\section{Patient Selection}

The Auckland District Health Board catchment area has 469,000 patients of which 5\% are affected by T2D (Wijayaratna, personal communication). It is one of three autonomous district health boards that is responsible for providing healthcare services to the 1.4 million patients in the Auckland Metropolitan area.
Included in the study were patients who had been referred for a review of their diabetes care by the duty nurse specialist at the tertiary clinical center, and who were initiated on insulin in 2012. Patients are referred to the clinical center from the Auckland Public Hospital (inpatient services), retinal screening programs, medical specialists or primary care.

All patients with T2D referred to the duty nurse specialist for the first time underwent comprehensive nutrition and self-management session, including the appropriate use of insulin and oral hypoglycemics as required. Written information and links to useful websites were also provided.

The decision to commence patients on insulin was taken in the course of normal clinical practice. All patients were initiated on one of three types of insulin: intermediateacting insulin isophane (human neutral protein Hagedorn) twice daily or at night, biphasic human insulin (pre-mix) twice daily or longacting once-daily insulin analog (glargine). These were the three commercially available insulin types that were subsidized by Pharmaceutical Management Agency (PHARMAC), the New Zealand drug-buying agency [10]. PHARMAC is a Crown entity established by the New Zealand Health and Disability Act 2000 and directly accountable to the Minister of Health [10]. The patient and diabetes clinicians together negotiated the choice of insulin, the starting dose, administration frequency and any later changes to dose or titration frequency.

Excluded from the study were patients with type 1 diabetes, new-onset diabetes after transplantation, steroid-induced diabetes, or latent autoimmune diabetes. In addition, the study excluded patients with T2D who were not started on insulin, and those without electronic medical records on insulin commencement. 
Figure 1 gives an overview of the patient selection process.

\section{Study Endpoints}

The primary outcomes were the proportion of patients achieving an HbA1C of $<55$ $\mathrm{mmol} / \mathrm{mol}$, rates of hospital admission for hypoglycemia, and weight change. These were analyzed on an intention to treat basis.

A patient was admitted to hospital if their blood sugar levels were less than $2.5 \mathrm{mmol}$, if their hypoglycemia was associated with a loss of consciousness defined as a Glasgow Coma Scale $<12$ or if they required intramuscular or intravenous glucose to relieve their symptoms. The purpose of admission was further monitoring and addressing the cause of hypoglycemia.

As secondary outcomes, factors that may influence physician choice of insulin at initiation were analyzed. Following the results of the A1chieve study [9], measurements of microvascular complications at baseline were taken, as well as duration of diabetes.

All the HbA1C results in the Auckland District Health Board were analyzed using a Siemens/ Bayer AG 2000+ analyzer (Bayer AG, Leverkusen, Germany) using the high-performance liquid chromatography method. The assay was Diabetes Control and Complications Trial aligned with a coefficient of variance of less than 5\% (personal communication). The range of values was $4-130 \mathrm{mmol} / \mathrm{mol}$ and normal values are quoted as 40-60 mmol/mol. An HbA1c target of $55 \mathrm{mmol} / \mathrm{mol}$ was used based on the New Zealand primary care handbook 2011 target for optimal control [11].

\section{Statistical Analysis}

Statistical analysis was performed by comparing the proportions as samples using Fisher's exact test as a non-parametric test and by performing multiple logistic regression with HbA1C $<55 \mathrm{mmol} / \mathrm{mol}$ and hospital admission for hypoglycemia as outcome measures. Age, duration of diabetes, ethnicity and dose of insulin were dependent variables. A multivariate logistic regression was used to fit a model that examined the primary outcomes. The first model examined the relationship between achieving HbA1C $<55 \mathrm{mmol} / \mathrm{mol}$ (binary outcome) and age, ethnicity, duration of diabetes, and type of insulin used. The second model examined the same variables and their relationship to hypoglycemia.

The Kruskal-Wallis test was used to compare paired HbA1C data pre- and post-insulin initiation for those with an HbA1C $>85 \mathrm{mmol} / \mathrm{mol}$. This was appropriate as the samples were not normally distributed.

Missing data were analyzed as zero values. Patients who had changed insulin therapy during the follow-up period did not have their values included for dose change of each insulin type. Statistical analysis was carried out using SPSS version 21.0 for Microsoft Windows platform. (SPSS Inc. Chicago, IL, USA).

\section{RESULTS}

\section{Patient Characteristics}

A total of 339 patients met the inclusion criteria. At 12 months following initiation, follow-up data were available on all (100\%) of these patients. Those that did not have electronic follow-up data had already been excluded (Fig. 1).

The baseline characteristics of those commenced on insulin are shown in Table 1. Of these, 273 (80.5) were commenced on intermediate-acting insulin isophane, 24 (7.1\%) were commenced on long-acting 


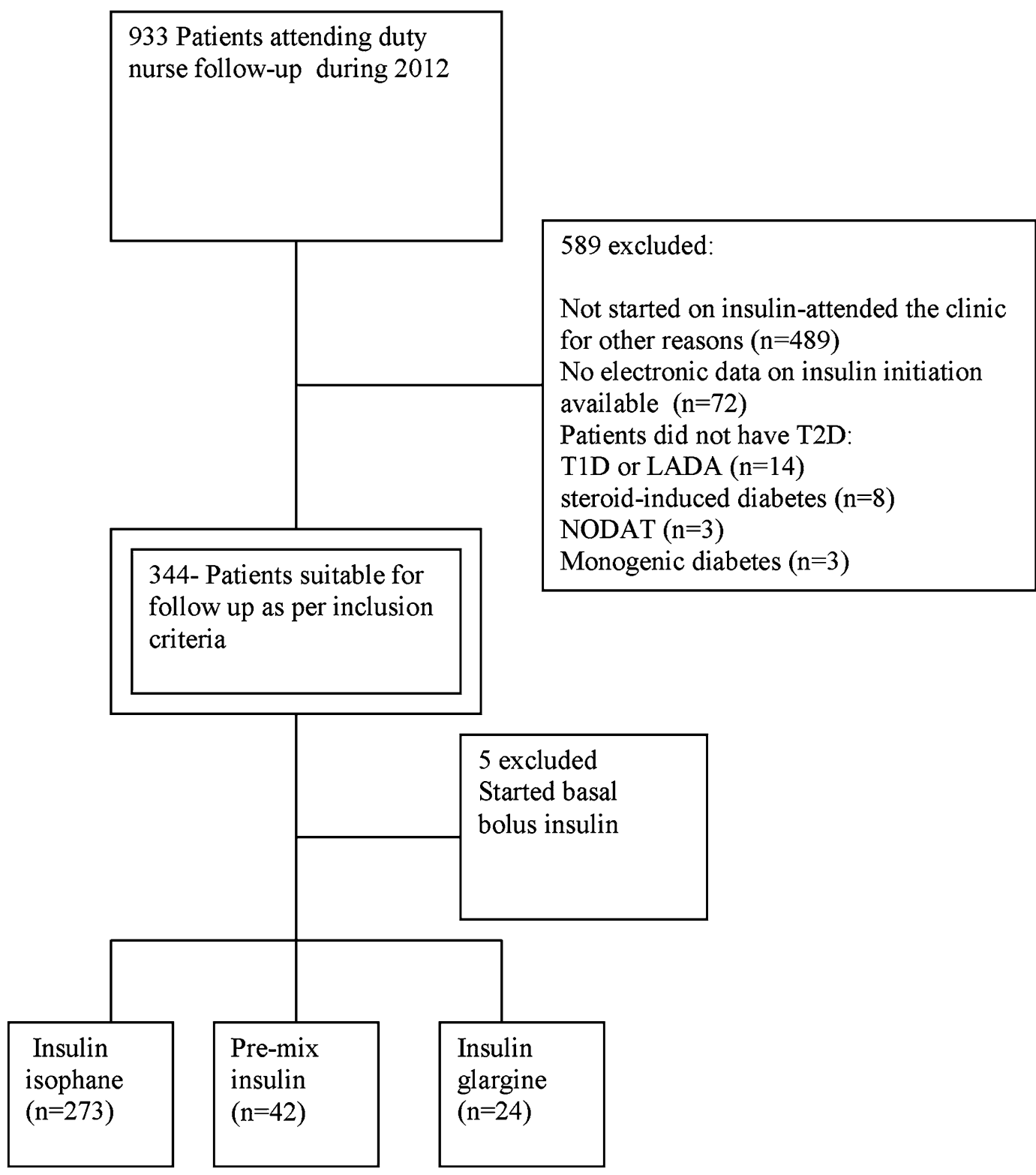

Fig. 1 Selection of eligible patients. $L A D A$ Latent autoimmune diabetes, NODAT new-onset diabetes after transplantation, $T 1 / 2 D$ type $1 / 2$ diabetes

insulin glargine once daily, and the remaining 42 (12.4\%) patients were commenced on biphasic pre-mixed insulin.

The mean age was 55.7 years in the insulin isophane group, 59.2 years in the glargine group and 56.7 years in the pre-mixed group. There was no statistically significant difference in age distributions between the three groups. There was also no statistically significant difference in terms of weight or BMI between the three groups (see Table 1).

Europeans (36\%) and Pacific Islanders (32\%) were the two largest ethnic groups of patients commenced on insulin. The remaining patients 
Table 1 Baseline characteristics

\begin{tabular}{|c|c|c|c|}
\hline & $\begin{array}{l}\text { Intermediate } \\
\text { insulin } \\
\text { isophane }\end{array}$ & $\begin{array}{l}\text { Long- } \\
\text { acting } \\
\text { insulin } \\
\text { glargine }\end{array}$ & $\begin{array}{l}\text { Biphasic } \\
\text { pre-mixed } \\
\text { insulin }\end{array}$ \\
\hline$n$ & 273 & 24 & 42 \\
\hline \multicolumn{4}{|l|}{ Sex, $n(\%)$} \\
\hline Male & $139(50.9)$ & $15(62.5)$ & $21(50.0)$ \\
\hline Female & $134(49.1)$ & $9(37.5)$ & $21(50.0)$ \\
\hline $\begin{array}{c}\text { Mean }(\text { SEM) } \\
\text { weight }(\mathrm{kg})\end{array}$ & $91.4(25.3)$ & $\begin{array}{l}86.0 \\
(21.5)\end{array}$ & $93.4(36.0)$ \\
\hline $\operatorname{BMI}\left(\mathrm{kg} / \mathrm{m}^{2}\right)$ & 31.6 & 31.5 & 32.3 \\
\hline $\begin{array}{c}\text { Mean (SEM) } \\
\text { age (years) }\end{array}$ & $55.7(13.9)$ & $\begin{array}{l}59.2 \\
(16.5)\end{array}$ & $56.7(11.4)$ \\
\hline $\begin{array}{l}\text { Mean (SEM) } \\
\text { duration of } \\
\text { diabetes } \\
\text { (years) }\end{array}$ & $10.6(6.7)$ & $9.2(6.6)$ & $12.0(9.8)$ \\
\hline $\begin{array}{l}\text { Poor glycemic } \\
\text { control }^{\text {a }} \\
n(\%)\end{array}$ & $114(41.8)$ & $11(45.8)$ & $21(50.0)$ \\
\hline $\begin{array}{l}\text { Median insulin } \\
\text { dose at } \\
\text { initiation } \\
\text { (units } / \mathrm{kg} \text { ) }\end{array}$ & 0.2 & 0.2 & 0.3 \\
\hline \multicolumn{4}{|c|}{ Oral hypoglycemic agents, $n(\%)$} \\
\hline Metformin & $210(76.9)$ & $16(66.7)$ & $33(78.6)$ \\
\hline Sulfonylurea & $186(68.1)$ & $17(70.8)$ & $13(31.0)$ \\
\hline Other & $10(3.7)$ & $3(12.5)$ & $1(2.4)$ \\
\hline
\end{tabular}

$B M I$ body mass index, SEM standard error of the mean

${ }^{a} p=0.013$ vs. intermediate-acting insulin isophane

b $p<0.05$ vs. intermediate-acting insulin isophane

were of Asian (23\%), Maori (5\%) or other (4\%) ethnicity.

The only statistically significant differences between groups at baseline were that those commenced on pre-mixed insulins were less likely to be on sulfonylureas than those started
Table 2 Primary and secondary outcome measures

\begin{tabular}{|c|c|c|c|}
\hline & \multicolumn{3}{|c|}{$\begin{array}{l}\text { Insulin modality at insulin } \\
\text { initiation }\end{array}$} \\
\hline & $\begin{array}{l}\text { Intermediate- } \\
\text { acting insulin } \\
\text { isophane } \\
(n=273)\end{array}$ & $\begin{array}{l}\text { Long- } \\
\text { acting } \\
\text { insulin } \\
\text { glargine } \\
(n=24)\end{array}$ & $\begin{array}{l}\text { Biphasic } \\
\text { pre- } \\
\text { mixed } \\
\text { insulin } \\
(n=42)\end{array}$ \\
\hline \multicolumn{4}{|c|}{ Mean (SEM) HbAlc, $\mathrm{mmol} / \mathrm{mol}$} \\
\hline At baseline & 89.3 & 95.4 & 93.4 \\
\hline $\begin{array}{l}\text { At } 12 \text { months } \\
\text { post-initiation }\end{array}$ & 72.7 & 68.9 & 70.0 \\
\hline $\begin{array}{c}\text { Mean (SEM) } \\
\text { HbA1C } \\
\text { reduction }\end{array}$ & $-16.6(4.00)$ & $\begin{array}{l}-26.6 \\
(10.60)\end{array}$ & $\begin{array}{r}-23.7 \\
(10.82)\end{array}$ \\
\hline $\begin{array}{l}\text { Patients achieving } \\
\text { HbA1C } \\
<55 \mathrm{mmol} / \mathrm{mol} \text {, } \\
n(\%)\end{array}$ & $13(4.8)$ & $4(16.7)^{\mathrm{a}}$ & $3(7.1)$ \\
\hline $\begin{array}{l}\text { Patients } \\
\text { continuing on } \\
\text { same insulin } \\
\text { type, } n(\%)\end{array}$ & $190(69.6)$ & $20(83.3)$ & $\begin{array}{l}38 \\
(90.5)^{b}\end{array}$ \\
\hline $\begin{array}{l}\text { Mean (SEM) } \\
\text { weight gain, kg }\end{array}$ & 1.9 & 1.1 & 0.9 \\
\hline $\begin{array}{l}\text { Patients } \\
\text { hospitalized for } \\
\text { hypoglycemia, } \\
n(\%)\end{array}$ & $11(4.0)$ & 0 & $5(11.9)$ \\
\hline
\end{tabular}

HbAlc glycated hemoglobin, SEM standard error of the mean

${ }^{a} p=0.04$ Fisher's exact test vs. isophane

b $p=0.01$ Fisher's exact test vs. isophane

on intermediate insulin $(31.0 \%$ vs. $68.1 \%$, $p<0.0001$, Fisher's exact test) (see Table 1), and those on pre-mixed insulin had a higher rate of retinopathy compared to those on intermediate-acting insulin $(48.8 \%$ vs. $20.8 \%$; $p=0.0001)$. The rates of all microvascular complications were higher in the pre-mixed 
group than those on intermediate-acting insulin and insulin glargine.

\section{HbA1C Lowering}

There was a statistically significant reduction in HbA1C at 1-year post-initiation of insulin across all insulin modalities. This was greatest for longacting insulin glargine (HbA1C reduction from 95.4 to $68.9 \mathrm{mmol} / \mathrm{mol} ; p<0.0001$, Student's $t$ test), followed by biphasic pre-mixed insulin (HbA1C reduction from 93.7 to $70.0 \mathrm{mmol} / \mathrm{mol}$; $p=0.0045)$ and intermediate-acting insulin isophane (HbA1C reduction from 89.3 to $72.7 \mathrm{mmol} / \mathrm{mol} ; p=0.0001$ ) (Table 2).

There was no significant difference between the three groups in the amount of HbA1C lowering at 1 year.

Twenty of the 339 patients $(5.9 \%)$ met the predetermined HbA1C target of $<55 \mathrm{mmol} / \mathrm{mol}$ at 1-year post-insulin initiation. Overall, 13 patients in the intermediate insulin group, 4 patients in the glargine group and 3 patients in the pre-mixed group met these targets. Those on insulin glargine were more likely to meet the HbA1C target than those on intermediateacting insulin ( $p=0.038$, Fisher's exact test).

In a subgroup of 146 patients with an $\mathrm{HbA1C}$ of $>85 \mathrm{mmol} / \mathrm{mol}$ at insulin initiation, premixed insulin was associated with a greater proportional reduction in HbA1C (Table 3). There was no statistically significant difference in the amount of HbA1C lowering between the three groups ( $p=0.272$, Kruskal-Wallis test).

\section{Dose Increases}

Those on insulin isophane and insulin glargine were started on an average dose of $0.2 \mathrm{U} / \mathrm{Kg}$ (15 and 19 units, respectively). Those on pre-mixed insulin were started on $0.3 \mathrm{U} / \mathrm{kg}$ (31 units).
Table 3 Odds of achieving HbA1C $<55$

\begin{tabular}{lll}
\hline Variable & $\begin{array}{l}\text { Odds ratio } \\
(\mathbf{9 5} \% \text { confidence intervals })\end{array}$ & $\boldsymbol{p}$ value \\
\hline Glargine insulin & $3.7(1.0,14.1)$ & 0.05 \\
Pre-mixed insulin & $1.9(0.5,7.4)$ & 0.37 \\
Isophane & 1.0 & \\
\hline
\end{tabular}

HbAlc glycated hemoglobin

After 1 year, there was only a modest dose increase $0.1 \mathrm{U} / \mathrm{kg}$ in the dose of insulin isophane or glargine and a $0.2 \mathrm{U} / \mathrm{kg}$ increase in pre-mixed insulin.

\section{Persistence Rates}

Overall, 190 of the 273 patients commenced on intermediate insulin continued using the same type of insulin at 1 year (69.6\%) compared to 20 of 24 on long-acting insulin glargine (83.3\%) and 38 of $42(90.5 \%)$ on biphasic pre-mixed insulin. Those on pre-mixed insulin were more likely to continue using the same type of insulin compared with those on intermediate-acting insulin ( $p=0.01$, Fisher's exact test). There was no statistically significant difference in the persistence rate between those commenced on insulin glargine and intermediate insulin ( $p=0.241$, Fisher's exact test).

In the subgroup of patients who persisted on intermediate-acting insulin, 96 (50.5\%) stayed on once-daily intermediate insulin, 74 (38.9\%) changed to twice-daily intermediate insulin from once-daily intermediate insulin, and $20(10.5 \%)$ were started on twice-daily intermediate insulin.

Of those who did not persist on insulin for 1 year, 62 of 83 patients who were initiated on intermediate isophane insulin were changed to pre-mix, 14 to insulin glargine and 7 to basal bolus. Among those started on insulin glargine, two were changed to basal bolus and two to pre- 
mixed insulin. Of the patients who were initiated on pre-mixed insulin, an equal number changed to insulin glargine and intermediate insulin.

\section{Hypoglycemia}

There were 16 hospital admissions for hypoglycemia at 1-year post-initiation of insulin (Table 2). Eleven hospitalizations were for patients initiated on intermediate insulin and five for patients on pre-mixed insulin. Patients initiated on insulin glargine did not develop hypoglycemia requiring hospitalization; however, this finding was not statistically significant $(p=0.6093$, Fisher's exact test). There was no correlation between type of insulin and hypoglycaemia rate, $p=0.465$, fisher's exact test.

\section{Weight Gain}

The mean weight gain across all three groups was comparable and there was no statistically significant difference between the three groups (Table 2). Patients on intermediate-acting insulin gained on average $1.9 \mathrm{~kg}$, those on insulin glargine $1.1 \mathrm{~kg}$ and those on pre-mixed insulin gained $0.9 \mathrm{~kg}$.

\section{Follow-Up Rates}

Overall, $33.9 \%$ of patients started on insulin were followed up at 1 month and $63.3 \%$ followed up at 3 months. In the isophane insulin group, $39.6 \%$ were followed up at 1 month, and $65.6 \%$ followed up at 3 months. Follow-up rates were lowest in patients on premixed insulin, with $21.3 \%$ of patients followed up at 1 month, and $58.3 \%$ at 3 months. Of those on insulin glargine 33\% were followed up at 1 month and $71.4 \%$ followed up at 3 months.
There was no significant difference in the HbA1C of groups with differing frequencies of follow-up at 1 year. The HbA1C outcomes arranged by follow-up duration are as below.

\section{Logistic Regression}

A binomial logistic regression model was constructed to explain variation in the rates of achieving the primary outcome HbA1C $<55$ $\mathrm{mmol} / \mathrm{mol}$, including age, ethnicity, starting and ending dose of insulin, and the presence of 3-month follow-up. The model had an $R^{2}$ value of 0.2 indicating that it was moderately predictive. A similar model for patients at risk of hypoglycemia was constructed using the same variables, and found no significant difference between the three insulin groups. Compared to isophane insulin, neither glargine (odds ratio [OR] 0.9) nor pre-mixed insulin (OR 0.87) was associated with a significantly different rate of hypoglycemia.

\section{DISCUSSION}

In this retrospective cohort study, the efficacy of the three most commonly used insulin modalities used to initiate therapy in insulinnaïve patients with $\mathrm{T} 2 \mathrm{D}$ was evaluated. A statistically significant reduction in $\mathrm{HbA1C}$ was achieved in the 12 months after insulin initiation, regardless of the type of insulin used. The mean reduction in HbA1C was between 17 and $27 \mathrm{mmol} / \mathrm{mol}$ in all groups. This study was an open-label, retrospective study conducted in a true clinical setting that chose to analyze clinically relevant endpoints.

In this New Zealand cohort of T2D patients, intermediate-acting insulin isophane was the most common type of insulin initiated. Physician factors known to impact on insulin choice include cost, availability, efficacy, and 
local clinical practice guidelines, as well as patient preference. There is a significant worldwide variation in the type of insulin prescribed first-line [12]. In the Southeast Asian cohorts of the Novo Nordisk-funded A1chieve study, more than $75 \%$ of patients were prescribed a pre-mixed insulin as their initial insulin, whereas in the rest of the world basal insulin was prescribed to the majority of insulin-naïve patients [9]. This choice may be influenced by local factors such as diet, as a high-carbohydrate diet with increased postprandial blood sugars may prompt more use of a regimen containing some form of shortacting insulin.

The choice of therapy may also be influenced by local medical practice. In a New Zealand context, PHARMAC manages the pharmaceutical schedule, and is responsible for the optimal use of medications and the allocation of subsidies for each medication or medication type [13]. The decision to fund a new medication is one that involves two subcommittees of PHARMAC, the Pharmacology and Therapeutics Advisory committee, representing clinical interests, and the Consumer Advisory Committee broadly representing consumer interests [10]. Guidelines play a vital role in influencing physician choice; the New Zealand primary care handbook recommends the use of isophane insulin at night and isophane insulin twice daily as first- and second-line treatments, respectively, for patients with $\mathrm{T} 2 \mathrm{D}$ requiring insulin [11]. It is used as a reference by physicians in training as well as specialists in hospital [11]. A more carbohydrate-rich diet with increased postprandial blood sugars may prompt use of a regime containing some form of short-acting insulin.

Patient factors that influence insulin choice include fear of injection, fear of complex insulin regimens as well as fear of hypoglycemia and weight gain [12]. The $4 \mathrm{~T}$ trial found that basalonly insulin was associated with less weight gain and fewer episodes of hypoglycemia compared with short-acting insulin regimens [4]. From both of these points of view, one can appreciate that intermediate-acting insulin has benefits as a first-line insulin therapy, but the efficacy may be less than that of other agents.

Patients initiated on insulin glargine were more likely to meet HbA1C targets, having adjusted for other confounding variables, and did not have hypoglycemic events requiring hospitalization in the 1-year post-insulin initiation. Several trials have found an increased chance of meeting HbA1C targets and low rates of all hypoglycemia, especially nighttime hypoglycemia in those commenced on insulin glargine $[2,5,7]$. While the low rates of hypoglycemia may be due to the peak-less mechanism of action, the Monnier hypothesis may help to explain effectiveness of insulin glargine in lowering HbA1C [14]. As HbA1C rises, the proportional contribution of fasting sugars to $\mathrm{HbA} 1 \mathrm{C}$ increases, and as a result those on basal insulin should have a greater proportional lowering of HbA1C [14]. In the small group of patients commenced on glargine in the preset study, patients were more likely to persist on insulin therapy than intermediate insulin, possibly due to the once-daily use of glargine as opposed to twice-daily use of isophane. These factors need to be explored with further, larger observational studies.

Patients initiated on pre-mixed insulin had more microvascular complications at baseline, were more likely to persist with insulin and there was greater proportional reduction of HbA1C in those with high HbA1C. Data from the Algerian cohort of the A1chieve study, found that pre-mixed insulin was more often prescribed with those with poor glycemic 
control and increased incidence of microvascular complications [12].

Although intermediate insulin was the most commonly initiated insulin, only 69\% of patients persisted on intermediate insulin at 1 year. More patients were likely to persist on insulin glargine, and even more still persisted on pre-mixed insulin in a statistically significant manner. In a large observational study based on US insurance claims, more patients persisted on insulin glargine in a statistically significant manner than other insulins [15]. Insulin glargine is usually initiated once daily, and most patients persist on once-daily regimens, whereas up to $40 \%$ of intermediate insulin patients have changed to twice-daily administration at 1 year [15]. This ease of administration with fewer injections may be a major contributing factor in more patients persisting with insulin glargine. The increased persistence of pre-mixed patients is unusual, and not widely documented in the literature [16]. In the local practice where this study was based, pre-mixed is generally instituted third line following once- and twicedaily basal insulin. Patients may be more keen to persist with it due to the absence of other viable insulin therapy, with the exception of basal bolus (too many injections) and insulin pump therapy which is not commonly used in New Zealand for T2D [11].

The study limitations included retrospective nature of the study and small sample size. This might have had a particular impact on both the insulin glargine and pre-mixed insulin groups where small sample size impeded the ability to detect known associations such as reduced rates of hypoglycemia with insulin glargine. An underlying cause could be selection bias, as insulin glargine was not subsidized for use in New Zealand for T2D until 2010 [17]. Even when it was subsidized for use it was used primarily in patients with a high perceived risk of hypoglycemia. The use of insulin glargine as a first-line agent is becoming more widespread not only because of its low rates of hypoglycemia, but also because of its singledose regimen, peak-less mechanism of action that ensures a flexibility of delivery time that is not available in standard human insulin [18]. The sample of acute referral patients in the present study may be a separate group than those outpatients treated in a standard way by medical and nursing specialist at the center. Finally another major limitation is the lack of patient satisfaction input and use of quality-oflife indicators. A recent follow-up from the A1chieve study has shown that patients had a statistically significant improvement in their quality of life upon starting or switching to long-acting analogs [19]. Further studies would have to address these and other limitations to gain more generalizability.

In a publically funded system, the cost effectiveness of any intervention should be considered. In New Zealand, the cost of a 300 -unit vial of glargine ( $\$ 100)$ is greater than that of the most commonly used pre-mixed insulin, Penmix 30 (Novo Nordisk Pharmaceuticals, Pakuranga Auckland, New Zealand) (\$42.67) with isophane being the cheapest of the three (\$28) [20]. Given that there is no overall difference in mean HbA1C lowering between the three groups, it may be more cost effective to consider isophane insulin as the preferred initiation insulin [20]. These value judgments must be made on a case-by-case basis.

This retrospective cohort study found that, at a clinical center in New Zealand, insulin is initiated in patients with T2D at a higher HbA1C threshold than it is in randomized controlled trials. Moreover, in clinical practice, patients who start insulin often have preexisting microvascular and macrovascular 
complications, and would therefore be excluded from many clinical trials. Initiating any insulin in this group, regardless of type, resulted in statistically significant reductions in mean HbA1C. Patients on insulin glargine were more likely to achieve HbA1c targets and did so with no hypoglycemic episodes in the 12-month follow-up period. Those who commenced on pre-mixed insulin had a higher rate of complications at outset but were more likely to persist on insulin therapy, with the suggestion of added benefit at higher HbA1C. The data suggest that, in clinical practice, most patients with T2D can be initiated on insulin glargine, but those with multiple pre-existing microvascular complications and very poor glycemic control may be initiated on premixed insulin to achieve better glycemic control and reduced morbidity from complications. This model of insulin initiation in clinical practice would need to be validated in larger observational and interventional studies.

\section{CONCLUSION}

Patients in the present study commenced on insulin at a much higher HbA1C than those in clinical trials. All types of insulin provided a statistically significant $\mathrm{HbA} 1 \mathrm{C}$ reduction at 1 year. Insulin isophane was the most common type of insulin initiated but it had comparable results to all other insulin types. Patients had a high rate of poor glycemic control, indeed few patients met the predetermined glycemic targets following 1 year of insulin therapy. Other types of insulin have some promising characteristics, although the subgroup sample size is too small to allow meaningful analysis.
While the optimal insulin initiation regimen in clinical practice has not yet been defined, these results highlight the importance of starting insulin (of any type) to achieve glycemic targets in patients with T2D and microvascular and macrovascular complications. Given the current and future burden of T2D in New Zealand, as in other developed countries, urgent action is needed to overcome therapeutic inertia, and thereby to limit wherever possible the humanistic and financial burden of diabetes-related complications.

\section{ACKNOWLEDGMENTS}

ADHB provided the research site and electronic access to data; they did not fund the article processing charges or provide direct funding for the study. No funding or sponsorship was received for this study or publication of this article. Editorial assistance in the preparation of this manuscript was provided by Catherine Rees of Rata Communications Inc, Auckland New Zealand. All named authors meet the ICMJE criteria for authorship for this manuscript, take responsibility for the integrity of the work as a whole, and have given final approval to the version to be published. We would like to thank Dr. P. Sehgal (ADHB) for reviewing the manuscript prior to submission.

Conflict of interest. Shekhar Sehgal and Manish Khanolkar declare that they have no conflicts of interest.

Compliance with ethics guidelines. This article does not contain any new studies with human or animal subjects performed by any of the authors. 
Open Access. This article is distributed under the terms of the Creative Commons Attribution Noncommercial License which permits any noncommercial use, distribution, and reproduction in any medium, provided the original author(s) and the source are credited.

\section{REFERENCES}

1. Fonseca VA. Defining and characterizing the progression of type 2 diabetes. Diabetes Care. 2009;32(supply 2):S151-6.

2. Holman RR, Paul SK, Bethel MA, Matthews DR, Neil HAW. 10-year follow-up of intensive glucose control in type 2 diabetes. $\mathrm{N}$ Engl J Med. 2008;359:1577-89.

3. Dunning T, Sinclair A, Colagiuri S. New IDF guideline for managing type 2 diabetes in older people. Diabetes Res Clin Pract. 2014;103:538-40.

4. Nathan DM, Buse JB, Davidson MB, Ferrannini E, Holman RR, Sherwin R, Zinman B, American Diabetes Association, European Association for Study of Diabetes. Medical management of hyperglycemia in type 2 diabetes: a consensus algorithm for the initiation and adjustment of therapy a consensus statement of the American Diabetes Association and the European Association for the Study of Diabetes. Diabetes Care. 2009;32:193-203.

5. Holman RR, Thorne KI, Farmer AJ, Davies MJ, Keenan JF, Paul S, et al. Addition of biphasic, prandial or basal insulin to oral therapy in type 2 diabetes. N Engl J Med. 2007;357:1716-9.

6. Buse JB, Wolffenbuttel BH, Herman WH, Shemonsky NK, Jiang HH, Fahrbach JL, Martin SA. DURAbility of basal versus lispro mix 75/25 insulin efficacy (DURABLE) trial 24-week results: safety and efficacy of insulin lispro mix 75/25 versus insulin glargine added to oral antihyperglycemic drugs in patients with type 2 diabetes. Diabetes Care. 2009;32:1007-13.

7. Arnolds S, Heise T, Flacke F, Sieber J. Common standards of basal insulin titration in type 2 diabetes. J Diabetes Sci Technol. 2013;7:771-88.

8. Tsai ST, Pathan F, Ji L, Yeung VTF, Chadha M, Suastika K, et al. First insulinization with basal insulin in patients with type 2 diabetes in a realworld setting in Asia. J Diabetes. 2011;3:208-16.

9. Shah SN, Litwak L, Haddad J, Chakkarwar PN, Hajjaji I. The $A_{1}$ chieve study: a 60,000-person, global, prospective, observational study of basal, meal-time, and biphasic insulin analogs in daily clinical practice. Diabetes Res Clin Pract. 2010;88(Suppl 1):S11-6.

10. Introduction to Pharmac. 2011. Available at: http:// www.pharmac.govt.nz/2011/09/16/01INTRO.pdf. Accessed Nov 5, 2014.

11. New Zealand Guidelines Group. New Zealand primary care handbook 2012. 3rd ed. Wellington: New Zealand Guidelines Group; 2012. Available from: http://www.health.govt.nz/about-ministry/ ministry-health-websites/new-zealand-guidelinesgroup. Accessed 24 Oct, 2014.

12. Malek R, Arbouche Z, Bachaoui M, Zinai S, Dahaoui A, Senoussaoui S, Salah-Mansour A. Criteria influencing the choice of starting insulin regimen in patients with type 2 diabetes in routine clinical practice: baseline data from the Algerian cohort of the A1chieve study. Diabetes Res Clin Pract. 2013;101:S45-9.

13. Auckland District Health Board Annual Plan 2012/2013. 2012. Available from: http://www. adhb.govt.nz/documents/ADHB_Annual_Plan_2012_ 13.pdf. Accessed 24, Oct 2014.

14. Monnier L, Lipinski H, Colette C. Contributions of fasting and postprandial plasma glucose increments to the overall diurnal hyperglycemias of type 2 diabetic patients: variations with increasing levels of HbA1C. Diabetes Care. 2003;26:881-5.

15. Wang L, Wei W, Miao R, Xie L, Baser O. Real-world outcomes of US employees with type 2 diabetes mellitus treated with insulin glargine or neutral protamine Hagedorn insulin: a comparative retrospective database study. BMJ Open. 2013;3(4): e002348. doi:10.1136/bmjopen-2012-002348.

16. Davies M, Storms F, Shutler S, Bianchi-Biscay M, Gomis R. Improvement of glycemic control in subjects with poorly controlled type 2 diabetes: comparison of two treatment algorithms using insulin glargine. Diabetes Care. 2005;28:1282-8.

17. Snippets: Insulin glargine and Ezetimibe 2010. Available from: http://www.bpac.org.nz/BPJ/2010/ october/snippets.aspx. Accessed Nov 5, 2014.

18. Gillies PS, Figgitt DP, Lamb HM. Insulin glargine. Drugs. 2000;59:253-60.

19. Shah S, Zilov A, Malek R, Soewondo P, Bech O, Litwak L. Improvements in quality of life associated with insulin analogue therapies in people with type 2 diabetes: results from the $\mathrm{A}_{1}$ chieve observational study. Diabetes Res Clin Pract. 2011;94:364-70.

20. Insulin. 2014. Available from: http://www. mimsonline.co.nz/insulin. Accessed Nov 20, 2014. 